\title{
The Influence of L-Arginine on Blood Pressure, Vascular Nitric Oxide and Renal Morphometry in the Offspring from Diabetic Mothers
}

\author{
MARIA DE FATIMA CAVANAL, GUIOMAR NASCIMENTO GOMES, ANDRE L. FORTI, SILVIA OLIVEIRA ROCHA, \\ MARIA DO CARMO PINHO FRANCO, ZULEICA B. FORTES, AND FRIDA ZALADEK GIL
}

Department of Physiology [M.F.C., G.N.G., A.L.F., S.O.R., F.Z.G.], Federal University of São Paulo - Unifesp/EPM, CEP 04023-900, São Paulo, Brazil; Department of Pharmacology [M.C.P.F., Z.B.F.], University of São Paulo, CEP 05508-070, Cidade Universitária, São Paulo, Brazil

\begin{abstract}
The present study was designed to evaluate the effects of L-arginine ( $\mathrm{L}$-arg) supplementation on blood pressure, vascular nitric oxide content, and renal morphometry in the adult offspring from diabetic mothers. Diabetes mellitus was induced in female rats with a single dose of streptozotocin $(50 \mathrm{mg} / \mathrm{kg})$, before mating. The offspring was divided into four groups: group C (controls); group DO (diabetic offspring); group CA (controls receiving 2\% L-arg solution dissolved in $2 \%$ sucrose in the drinking water) and group DA (DO receiving the L-arg solution). Oral supplementation began after weaning and continued until the end of the experiments. In DO, hypertension was observed, from 3 mo on. In DA, pressure levels were not different from $\mathrm{C}$ and CA. In 6-mo-old animals, basal NO production (assessed by DAF-2) was significantly depressed in DO in comparison to controls. The NO production was significantly increased after stimulation with Ach or BK in all groups, the increase being greater in control than in DO rats. L-Arg was able to improve the NO production and to prevent the glomerular hypertrophy in the DO. Our data suggest that the bioavailability of NO is reduced in the DO, because L-arg corrected both the hypertension and glomerular hypertrophy. (Pediatr Res 62: 145-150, 2007)
\end{abstract}

$\mathrm{T}$ The correlation between fetal growth conditions and susceptibility to several pathologies in adulthood, including hypertension, diabetes, stroke, and coronary heart disease, have been identified (1-3). Maternal diabetes has been long known to be a clinical condition that is associated with high rates of spontaneous abortion, congenital malformations and perinatal mortality (4-7). The malformations result from defects occurring in early organogenesis including failure of neural tube closure, caudal regression syndrome, and urogenital abnormalities, which can be as severe as renal agenesis $(8,9)$. On the other hand, several studies suggested that offspring of diabetic mothers might be at an increased risk for the development of vascular disease and diabetes later in life (10-12). Holemans et al. (13) have suggested that maternal diabetes may also have lasting adverse consequences on cardiovascular function of the next generation, particularly be-

Received November 16, 2006; accepted March 26, 2007.

Correspondence: Frida Zaladek Gil, M.D., Ph.D., Department of Physiology, Federal University of São Paulo, UNIFESP-EPM, Rua Botucatu, 862, 5, CEP: 04023-900, São Paulo SP, Brazil; e-mail: frida@ecb.epm.br

This work was supported by grants from the Fundação de Amparo à Pesquisa do Estado de São Paulo (FAPESP). cause offspring of diabetic pregnant rats demonstrate overt insulin resistance in adulthood. Impaired nephrogenesis has been shown in the offspring from rats submitted to hyperglycemia during pregnancy (14).

In a previous study, we have demonstrated that maternal diabetes promotes remarkable changes in both kidney function and vascular reactivity in the mature offspring (15). Our data concerning diabetic offspring model (DO) pointed to an interesting model in which, although a normal nephron number was observed, two important factors-systemic hypertension and glomerular hypertrophy - which contribute to the progression of renal disease, were present. In fact, a significant increase in glomerular area concomitant to decreases in renal functional parameters was observed in 3-, 6-, and 12 mo-old DO. In 12-mo-old rats, a decrease in mesenteric arterial bed relaxation induced by acetylcholine and bradykinin was also obtained, whereas no differences could be detected to sodium nitroprusside. Therefore, we could suggest that it is not the smooth muscle vasodilating capability that is reduced in mesenteric bed from offspring of diabetic rats, but some function related to the endothelium.

In another series of experiments, we could show that, in an experimental model of intrauterine food restriction, (IU) in which a known reduction in nephron number is observed, administration of L-arginine ( $\mathrm{L}-\mathrm{arg}$ ) was able to prevent proteinuria and hypertension but did not avoid glomerular injury (16-20). A disturbance in the pathway L-arg-nitric oxide (NO) was postulated to be one of the causes of hypertension and glomerular injury. In fact, L-arg has been reported to improve renal functional parameters in several pathologic conditions such as 5/6 nephrectomy, diabetic nephropathy, hypercholesterolemia, and aging (21-24). Therefore, the present study was designed to evaluate the possible effects of L-arg supplementation on blood pressure, vascular NO production, and renal functional and morphometric parameters in the offspring from diabetic mothers. With this maneuver, we attempt to evaluate not only the blood pressure response to L-arg in this model but also the role of hypertension in the

Abbreviations: PAH, paraaminohippurate; STZ, streptozotoan 
development of glomerular hypertrophy in an experimental model with a preserved nephron number.

\section{METHODS}

All procedures used in this study were approved and performed in accordance with guidelines of the Ethics Committee of Biomedical Institute, Federal University of São Paulo and conformed to the Guide for Care and Use of Laboratory Animals (25). Wistar rats from our colony (Federal University of São Paulo) were maintained in a room at $22 \pm 1{ }^{\circ} \mathrm{C}$ with a 12 -h light cycle and $60 \%$ humidity.

Animals. Diabetes mellitus was induced by STZ $(50 \mathrm{mg} / \mathrm{kg})$ given by a single intraperitoneal injection to female Wistar rats (250-300 g). Control animals were given an equivalent amount of citrate buffer. Diabetic state was confirmed $48 \mathrm{~h}$ after, by measuring blood glucose. Only those animals with glycemic levels above $250 \mathrm{mg} / \mathrm{dL}$ were considered for mating. After 3-7 d of diabetic state confirmation, the rats were caged overnight with a male. Vaginal smears were taken in the following morning and a positive smear was considered as d 0 of gestation. All dams were housed and fed individually with the same diet. After birth, each litter, consisting of six male rats, was left with the mother for $28 \mathrm{~d}$; if the male number was not enough to complete six, females were used but discarded at weaning. The offspring were divided into four subgroups: group C (controls), group DO (diabetic offspring), group CA (controls receiving 2\% L-arg solution dissolved in $2 \%$ sucrose in drinking water, and group DA (diabetic offspring receiving L-arg solution dissolved in sucrose in drinking water). Rats in the $\mathrm{C}$ and DO groups received a $2 \%$ sucrose-only solution. The L-arg dose was similar to that used by Reckelhoff et al. (24), and the sucrose solution was used as a vehicle to improve L-arg ingestion. Supplementation with the L-arg solution or the sucrose-only solution began immediately after weaning and was continued until the end of the experimental protocol. Study rats received $1.2 \mathrm{~g} \mathrm{~L}-\mathrm{arg} / \mathrm{kg}$ bw/d. Glycemia was measured in newborn rats (NB), $12 \mathrm{~h}$ after delivery, and in 12-h fasted adult rats, every month. Arterial pressure was evaluated monthly, from 3 mo of age, by tail plethysmography. Renal function and kidney morphometry were evaluated in 3- and 6-mo-old rats.

Renal function studies. The animals were anesthetized with sodium thiopental $(30 \mathrm{mg} / \mathrm{kg})$ and placed on a heated table to maintain body temperature at $37^{\circ} \mathrm{C}$. Tracheotomy was followed by insertion of polyethylene catheters into the jugular vein for infusions, and into the carotid artery for blood sampling. Urine was collected from a catheter inserted into the bladder. After the surgical procedure, a 1-h stabilization period was allowed before the beginning of the collection periods. The animals were primed with $1 \mathrm{~mL}$ of saline containing inulin $(300 \mathrm{mg} / \mathrm{kg}$, and sodium PAH $(2 \mathrm{mg} / \mathrm{rat})$ and then submitted to continuous infusion of a saline solution containing inulin (15 $\mathrm{g} / \mathrm{L})$ and PAH $(4 \mathrm{mg} / \mathrm{L})$ at $0.08 \mathrm{~mL} / \mathrm{min}$. Plasma and urine inulin and PAH concentrations were measured by colorimetry for estimation of GFR and renal plasma flow (RPF). Blood and urine $\mathrm{Na}+$ were measured using ion selective electrode (Ciba-Corning $614 \mathrm{Na}^{+} / \mathrm{K}^{+}$analyzer, Ciba Corning, Halstead, UK). For protein excretion determination, rats were placed in metabolic cages and a 24-h urine collection was performed. Protein concentration was measured by precipitation with $3 \%$ sulfosalicylic acid.

Morphometric study. The morphologic evaluation was obtained by the following methodology: both kidneys from five rats of each group were dissected out rapidly, cleaned of connective tissue, weighed, and fixed in Bouin. Kidneys were longitudinally cut and wax embedded. Histologic sections (5 $\mu \mathrm{m}$ width) near renal hilus were performed. Sections cut were stained with hematoxylin and eosin to morphologic analysis. Glomerular area and diameters were measured using an image analysis program, Image-Pro PLUS (Media Cybernetica, Cambridge, UK). Images were acquired in microscope (Leica DMLB, Wetzlar, Germany) connected to a microcomputer by a video camera (Sony-CCD-IRIS). Ten different images (fields) in 10 different slides were analyzed for each group. Two different investigators who were unaware of the origin of the specimens performed this study.

Measurement of systolic blood pressure. Systolic blood pressure was determined in conscious rats by an indirect tail-cuff method (Harvard Apparatus, Endembridge, UK). Systolic pressure levels were measured from 3 to 6 mo of age. Rats were systematically trained before the measurements, to avoid stress effects. Animals were placed in the restrainers for several times. The restrainer was covered with a dark tissue; after this step, the animals remained calm and the pressure records were made after 15-20 min of quietude, without temperature variations. The measures were always performed by the same person. Three consecutive measures were taken and if a great variability was found, all the values were discarded and in the following day, the procedures were repeated. Rats were preheated at $39^{\circ} \mathrm{C}$ for $5 \mathrm{~min}$, and, then, three stable consecutive measurements of blood pressure were averaged.
Evaluation of NO production by DAF-2. NO was measured by the use of 4,5-diaminofluorescein diacetate (DAF-2), an NO-sensitive fluorescent dye. Aorta segments from 6-mo-old rats ( $n=4$ /group) were embedded in tissue freezing medium, snap-frozen, and stored at $-80 \mathrm{C}$. Cryosections, $7-\mu \mathrm{m}$ thick, were cut and then placed on slides. The aortic sections were incubated at $37^{\circ} \mathrm{C}$ with $12.5 \mu \mathrm{M}$ DAF-2 in $0.1 \mathrm{M}$ phosphate buffer (pH 7.4) containing $0.45 \mu \mathrm{M}$ $\mathrm{CaCl}_{2}$. After $1.5 \mathrm{~h}$, the sections were stimulated with $\mathrm{ACh}\left(10^{-4} \mathrm{M}\right)$ or $\mathrm{BK}$ $\left(10^{-4} \mathrm{M}\right)$. Control sections received the same volume of phosphate buffer. After an additional $1 \mathrm{~h}$, digital images were collected in a microscope with $\times 40$ objective lens, equipped for fluorescence (excitation at $485 \mathrm{~nm}$; emission $538 \mathrm{~nm}$ ). The images were analyzed using an image software by measuring the mean OD of the fluorescence observed in the endothelium. This fluorescence was evaluated in at least three locations in each image and in at least four aortas from different animals.

Statistical analysis. Statistical analysis was performed by unpaired $t$ test, Mann-Whitney $U$ test, or by ANOVA, followed by the Scheffé or Bonferroni test, where appropriate. Values that were not normally distributed were subjected to the Kruskal-Wallis test, followed by Dunn's post test, when necessary. Statistical significance was defined as $p<0.05$. The results are reported as means \pm SEM.

\section{RESULTS}

Effect of maternal diabetes and $L$-arg supplementation on body and kidney weight, glycemia, and blood pressure levels in the adult offspring. As shown in Table 1, with time, all the groups exhibited body weight gain. Kidney weight rose with increasing body weight and age but relative kidney weight did not change in all studied groups. Glycemia remained at normal levels in all groups. As shown in Figure 1, blood pressure levels were significantly increased in 3-mo-old DO rats (DO3). This hypertension persisted until the end of the experimental period. L-Arg administration did not change the blood pressure levels in control rats but caused a significant decrease in the diabetic offspring (DA) during all the experimental periods.

Effect of maternal diabetes and $L_{\text {-arg }}$ supplementation on renal function and morphometric study. As shown in Table 2, GFR was significantly decreased in 3-mo-old diabetic offspring when compared with 3-mo-old controls (C3). RPF was also proportionally decreased, leading to a preserved filtration fraction. With age, diabetic offspring showed a pronounced decreased in GFR and in U/P inulin, still maintaining filtration fraction (FF) within normal limits. Supplementation with L-arg did not change GFR in 6-mo-old rats in either control or diabetic offspring, when compared with the same group without L-arg. In DO6 rats, there was a significant

Table 1. Effect of maternal diabetes and L-arg on offspring body and kidney weight

\begin{tabular}{lccc}
\hline & Body weight $(\mathrm{g})$ & Kidney weight $(\mathrm{g})$ & $\begin{array}{c}\text { Kidney weight } \\
(\% \text { of body weight })\end{array}$ \\
\hline C3 & $381.1 \pm 4.54(20)$ & $1.32 \pm 0.05(18)$ & $0.40 \pm 0.002(18)$ \\
DO3 & $382.4 \pm 3.87(20)$ & $1.29 \pm 0.02(20)$ & $0.33 \pm 0.006(20)$ \\
CA3 & $343.5 \pm 12.9(9)$ & $1.16 \pm 0.09(14)$ & $0.39 \pm 0.005(9)$ \\
DA3 & $358.1 \pm 11.5(11)$ & $1.34 \pm 0.05(10)$ & $0.39 \pm 0.015(10)$ \\
C6 & $400.6 \pm 5.9(20)$ & $1.32 \pm 0.03(20)$ & $0.33 \pm 0.005(20)$ \\
DO6 & $410.7 \pm 4.2(20)$ & $1.41 \pm 0.04(20)$ & $0.34 \pm 0.008(20)$ \\
CA6 & $469.5 \pm 10.3+\ddagger(10)$ & $1.52 \pm 0.04(10)$ & $0.33 \pm 0.30(10)$ \\
DA6 & $413.12 \pm 11.7 \S(9)$ & $1.41 \pm 0.03(10)$ & $0.36 \pm 0.02(9)$ \\
\hline
\end{tabular}

Data are expressed as mean \pm SEM. Number in parenthesis are the number of animals in each group. Significance level, $p<0.05$. Comparisons are made between offspring from control and diabetic mothers at the same age, and between groups, at different ages. Number after the letter indicates the age of the animals, in months. $\dagger v s \mathrm{CA} 3$; $\ddagger v s \mathrm{C} 6$; $\S$ vs DA3. 


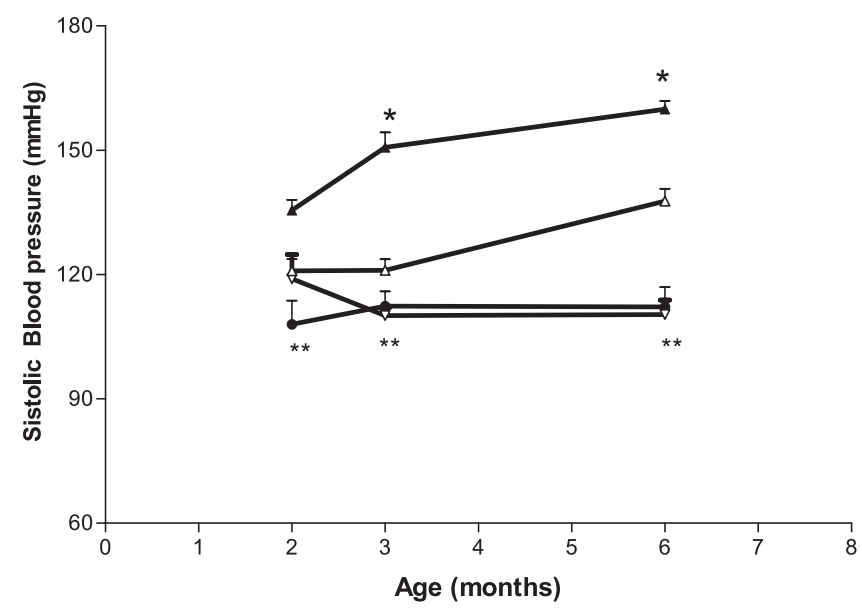

Figure 1. Effect of L-arg on blood pressure (BP) in control (C), $\mathrm{C}+\mathrm{L}-\arg$ (CA), diabetic offspring (DO), and diabetic offspring $+\mathrm{L}-\arg (\mathrm{DA})$ at different ages. $\triangle, \mathrm{C} ; \mathbf{\Lambda}, \mathrm{DO} ; \mathrm{V}, \mathrm{CA} ; \boldsymbol{\bullet}, \mathrm{DA}$. Administration of L-arg did not change the $\mathrm{BP}$ of $\mathrm{C}$ rats but promoted a significant decrease in the DA. Comparisons were made among animals of the same age, with or without L-arg administration. Number of measurements, $n=18$ for all the groups. Significance level: $p<$ $0.05(* \mathrm{C} v s \mathrm{DO}, * * \mathrm{DO}$ vs $\mathrm{DA})$

decrease in GFR compared with both C6 and DO3 rats, suggesting additional impairment in GFR caused by maternal diabetes, which accentuated the natural age-related decay of this parameter. These results are similar to those obtained by Rocha et al. (15) in 12-mo-old DO. Proteinuria was not observed in either group. As also shown in this table, in all groups evaluated at 3 mo of age, fractional excretion of $\mathrm{Na}$ $\left(\mathrm{FENa}^{+}\right)$was maintained within normal limits. L-Arg was able to prevent the increase in $\mathrm{FENa}^{+}$observed in 6-mo-old DO rats. In fact, in DA6, the $\mathrm{FENa}^{+}$returned to normal levels, suggesting that $\mathrm{Na}^{+}$conservation was improved by L-arg. Mean glomerular diameter and area were significantly greater in DO3 and DO6 animals, when compared with respective controls, at the same age (Fig. 2 and 3, respectively). L-Arg did not cause significant changes in glomerular diameter and area from both 3- and 6-mo control groups. In DA3 and DA6, glomerular diameter and area returned to values comparable to those exhibited by control groups.

Effect of maternal diabetes and L-arg supplementation on vascular NO production of the adult offspring. As shown in Figure 4, we directly assessed NO production by DAF-2 and observed that basal NO production was significantly depressed in DO in comparison with controls (Fig. 4A). The NO production was significantly increased after stimulation with Ach (Fig. 4B) or BK (Fig. 4C) in all groups, the increase being greater in control than in DO rats (Fig. $4, B$ and $C$ ). On the other hand, the L-arg treatment was able to improve the NO production in the DO offspring (Fig. 4, $A-C$ ).

\section{DISCUSSION}

It has been long known that infants born to diabetic mothers are at high risk for perinatal morbidity and mortality. In 1991, Hales et al. (2) showed that a strong correlation between low birth weight and glucose intolerance in elderly men was observed. In 1998, Nelson et al. (26) observed in Pima Indians that exposure to maternal diabetes increased the risk of elevated urinary albumin excretion in the offspring. Srinivasan et al. (27) suggested that in the rat, dietary modifications in the early postnatal life of the mothers set up a vicious cycle of spontaneous transfer of mothers phenotype to the progeny regarding insulin metabolism. This observation was confirmed by a recent study by Aerts and Van Assche (28).

Previously, our group showed that STZ-induced maternal diabetes causes hypertension and changes in vascular reactivity related to decrease in endothelium-dependent vasodilatation in 12-mo-old rats. No alteration in nephron number and in renal morphology was observed in the young offspring $(15,29)$. In the study from Magaton et al. (29), immunohistochemical analysis for antiproliferating cell nuclear antigen (PCNA), an index of growth rate, and for $\alpha$-SM-actin, overexpressed during pathologic states, showed a similar pattern in both $\mathrm{C}$ and DO groups; these results confirm previous data from our group which indicate no renal morphologic changes in the young and adult offspring from diabetic mothers (15).

In the present study, we confirm that the early presence of hypertension in DO is prevented by L-arg. Moreover, we were able to suggest that transmission of high-pressure levels to glomerular vasculature may be one of the main causes of glomerular hypertrophy. In fact, the normalization of blood pressure in DA was concomitant to the return to normal diameter and glomerular area.

Glomerular hypertrophy is known to be the early event in the progression of glomerular damage (30,31). We suggest that in the DO model, the early presence of high blood pressure levels may have deleterious effects to glomeruli, leading to hypertrophy. The role of systemic hypertension in the progression of renal disease has been long known $(32,33)$.

Table 2. Parameters of renal function in the offspring of diabetic rats

\begin{tabular}{|c|c|c|c|c|c|}
\hline & GFR $\mathrm{mL} / \mathrm{min} / \mathrm{kg}$ & $\mathrm{RPF} \mathrm{mL} / \mathrm{min} / \mathrm{kg}$ & $\mathrm{U} / \mathrm{P}$ & $\mathrm{FF} \%$ & $\mathrm{FENa} \%$ \\
\hline $\mathrm{C} 3$ & $7.02 \pm 0.45(22)$ & $18.97 \pm 1.87(22)$ & $54.1 \pm 2.03(22)$ & $35.8 \pm 0.50(22)$ & $0.46 \pm 0.07(22)$ \\
\hline DO3 & $4.40 \pm 0.12 *(18)$ & $15.9 \pm 0.99(18)$ & $40.4 \pm 1.14 *(18)$ & $30.1 \pm 1.50(18)$ & $0.40 \pm 0.03(18)$ \\
\hline CA3 & $5.37 \pm 1.03 *(16)$ & $11.85 \pm 0.8 *(16)$ & $50.9 \pm 1.77(16)$ & $47.8 \pm 3.15 *(16)$ & $0.52 \pm 0.07(17)$ \\
\hline C6 & $4.70 \pm 0.35^{*}(30)$ & $12.0 \pm 0.80 *(30)$ & $50.7 \pm 2.36(30)$ & $40.9 \pm 1.5(30)$ & $0.45 \pm 0.03$ \\
\hline D06 & $2.75 \pm 0.12 * * \ddagger(25)$ & $11.09 \pm 1.23(25)$ & $39.0 \pm 2.25 \div(25)$ & $32.0 \pm 2.2 \S(25)$ & $1.07 \pm 0.31 * *(28)$ \\
\hline CA6 & $4.72 \pm 0.22(16)$ & $14.56 \pm 0.94(16)$ & $56.7 \pm 3.18(16)$ & $33.3 \pm 1.33 \dagger(16)$ & $0.55 \pm 0.12(16)$ \\
\hline
\end{tabular}

Data are expressed as mean \pm SEM. Numbers in parentheses are the number of experiments. Significance level, $p<0.05$. Comparisons are made between offspring from control and diabetic mothers at the same age, between the same groups at different ages and between groups with or without L-arg.

* vs $\mathrm{C} 3$; ** vs DO3; $\dagger$ vs $\mathrm{CA} 3$; $\neq$ vs $\mathrm{C} 6$; $\|$ vs $\mathrm{CA} 6$; § vs DA3; If vs DO6. 


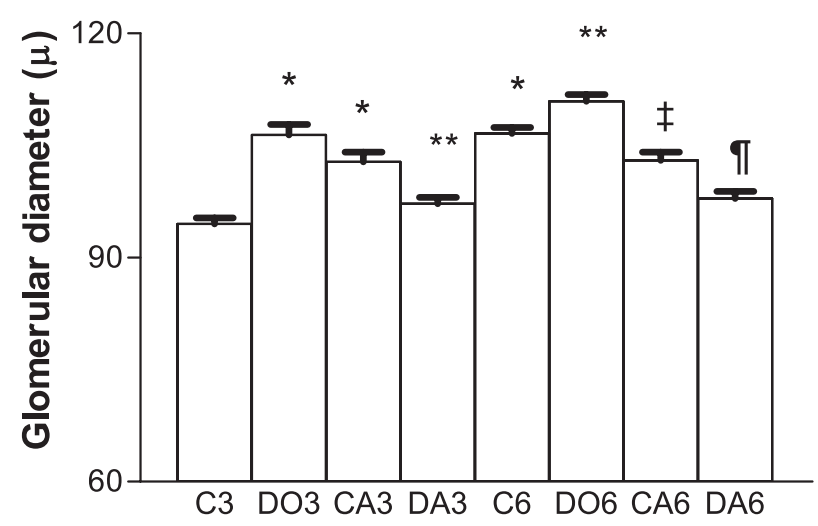

Figure 2. Mean glomerular diameter in the offspring from control and diabetic offspring with or without L-arg supplementation. Data from control $(\mathrm{C} 3, n=297$; C6 = 365), C plus L-arg (CA3, $n=138$, CA6, $n=126)$, diabetic offspring (DO3, $n=272$; DO6, $n=358$ ) and diabetic plus L-arg (DA3, $n=197$; DA6, $n=152$ ). Number after the letter indicates the age of the animals, in months. Significance level, $p<0.05$. Comparisons are made between offspring from control and diabetic mothers at the same age, and between groups, at different ages, with or without L-arg. *vs $\mathrm{C} 3$; **vs DO3; \$vs C6; Ivs DO6.

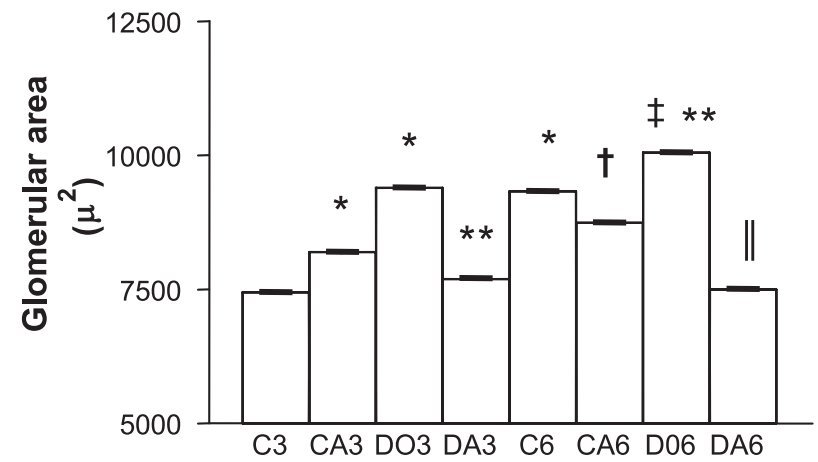

Figure 3. Mean glomerular area in the offspring from control and diabetic offspring with or without L-arg supplementation. Data from control (C3, $n=$ 297; C6 = 365), C plus L-arg (CA3, $n=138 ;$ CA6, $n=126)$, diabetic offspring (DO3, $n=272$; DO6, $n=358$ ), and diabetic plus L-arg (DA3, $n=197$; DA6, $n=152$ ). Number after the letter indicates the age of the animals, in months. Significance level, $p<0.05$. Comparisons are made between offspring from control and diabetic mothers at the same age, and between groups, at different ages, with or without L-arg. *vs $\mathrm{C} 3$; **vs DO3; $\dagger v s \mathrm{CA} 3 ; \ddagger v s \mathrm{C} 6$; $\| v s$ CA6.

A constant increase in blood pressure can be transmitted to glomeruli, leading to progressive injury, which can, in turn, aggravate systemic hypertension. On the other hand, both clinical and experimental studies have implicated nephron number as a crucial factor in determining hypertension. However, in the IU model, even in the presence of a normal blood pressure (after L-arg chronic administration), we could demonstrate that although attenuated, the progression to nephrosclerosis was maintained in 12-mo-old rats, suggesting that total nephron number is fundamental concerning the evolution to nephrosclerosis (20). Because in the present study we have used the DO model, which exhibits a conserved nephron number (15), compensatory hypertrophy would not be a valid explanation. However, other hypertrophic stimuli could be present, e.g. transforming growth factor- $\beta$ is known to be present in the glomeruli of human and experimental diabetes
A

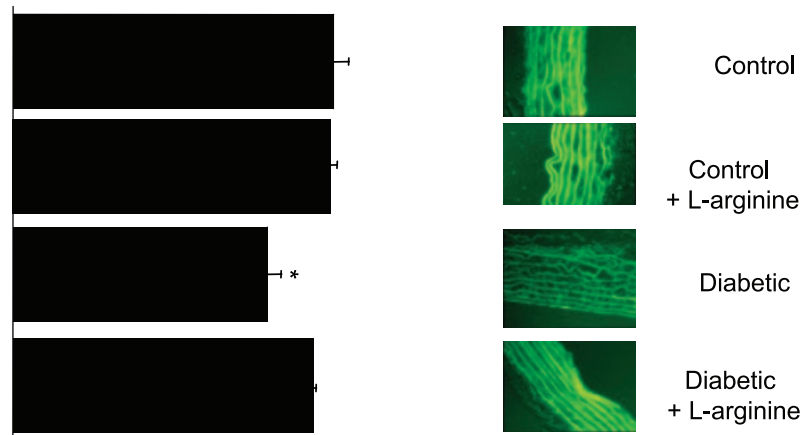

B
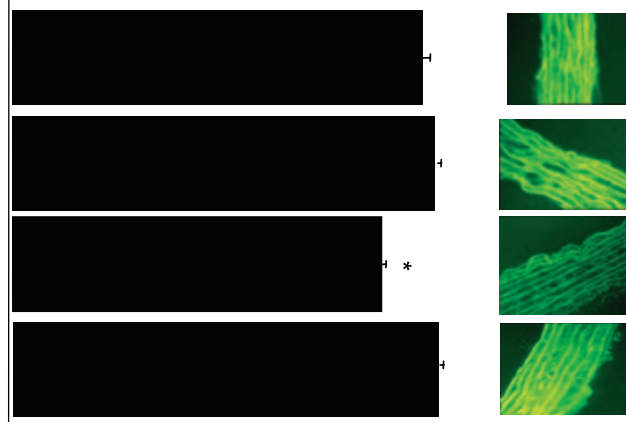

Control

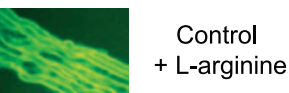

Diabetic

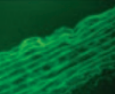

Diabetic

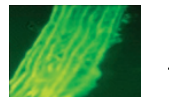

+ L-arginine

C
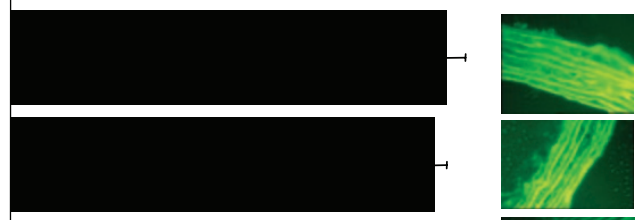

Control
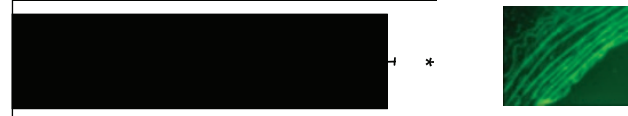

+ L-arginine
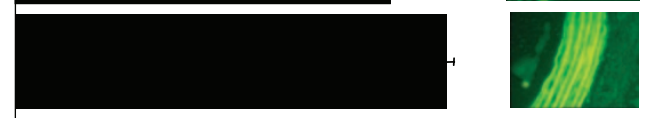

Diabetic

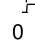

20

Imnunoreactivity index (labelingbackground)

Figure 4. Quantification of DAF-2 fluorescence and representative highpower photomicrograph of the aortic rings. $(A)$ Under basal conditions; $(B)$ after stimulation with $\mathrm{ACh}\left(10^{-4} \mathrm{M}\right)$ and $(C)$ after stimulation with $\mathrm{BK}\left(10^{-4}\right.$ M). ${ }^{*} p<0.05$ vs control; control plus L-arg or diabetic plus L-arg.

and could be transferred to the offspring, leading to glomerular hypertrophy.

In the kidney, NO exerts several physiologic roles, including regulation of glomerular hemodynamics, inhibition of $\mathrm{Na}^{+}$reabsorption with consequent augmentation of diuresis (34). The importance of NO in regulating blood pressure and glomerular hemodynamics was previously demonstrated by Zatz et al. (35). These authors showed that administration of NO synthase blockers to normal rats leads to changes in both systemic blood pressure levels and glomerular hemodynamics, with consequent nephrosclerosis.

In normal conditions, L-arg amounts in the plasma or in the vessels are well above the metabolic requirements since they are in excess of the $\mathrm{Km}$ of $\mathrm{NO}$ synthase enzymes. In patients with severe kidney diseases, renal production of L-arg can be lower than normal, as a result of a decreased substrate availability $(36,37)$. This hypothesis could be valid in our diabetic 
offspring, since an important decline in GFR was obtained in both studied ages. Although L-arg may also act as a vasodilator in arteriolar resistance, GFR did not return to normal levels in DA. L-Arg action seems to be age-dependent, as shown in our previous work (18). In 8-wk-old rats, L-arg was able to increase GFR both in control and in IU, but this ability was lost when animals reached $12 \mathrm{wk}$. On the other hand, in DA6, FF increased while $\mathrm{FENa}^{+}$assumed normal values. This apparent normalization of $\mathrm{Na}^{+}$tubular handling could be due to several mechanisms. One possibility is that the preferential action of $\mathrm{NO}$ on the afferent end could result in an increased load of $\mathrm{Na}^{+}$to the more distal parts of nephron, triggering the myogenic or the tubuloglomerular feedback, resulting in decreased amounts of $\mathrm{Na}^{+}$being excreted. Another possibility is the direct effect of $\mathrm{NO}$ on the $\mathrm{Na}^{+}-\mathrm{K}^{+}$-ATPase activity but conflicting results have been reported concerning the effects of $\mathrm{NO}$ on $\mathrm{Na}^{+}$tubular handling $(38,39)$ : inhibition of proximal $\mathrm{Na}^{+}-\mathrm{K}^{+}$-ATPase could lead to an increased load of $\mathrm{Na}^{+}$to the distal parts of the nephron and a consequent augmentation in total $\mathrm{Na}^{+}$reabsorption. However, the occurrence of the pressure-dependent natriuresis as a consequence of the normalization of blood pressure in DA may also explain the normal FE $\mathrm{Na}^{+}$in DA group.

The present data suggest that hypertension may be one of the primary causes of glomerular hypertrophy in DO. This latter concept is sustained by our studies with DAF-2, which directly assessed the production of NO in the vessels; in fact, maternal diabetes provoked a decrease in NO synthesis of the adult offspring. This finding is in agreement with our previous observations on vascular reactivity of the mesenteric microvessels, which have reported that severe maternal diabetes can led to vascular dysfunction in adult offspring, characterized by abnormal endothelium-dependent relaxation to acetylcholine and bradykinin in small mesenteric arteries (15).

Although alterations in L-arg -NO pathway have already been described in diabetic patients and in STZ-induced diabetes $(40,41)$, the relationship between hypertension and glomerular hypertrophy in the offspring from diabetic mothers is an original finding. In diabetic patients, L-arg concentration was shown to be reduced in the plasma and in lacrimal fluid $(42,43)$. A similar decrease was also shown in the plasma and aorta of diabetic animals $(40,44)$. On the other hand, L-arg has been shown to improve the diabetes-related endothelium dysfunction $(41,44)$. Moreover, L-arg has been shown to reduce the vascular release of superoxide and to restore NO production (23).

The involvement of the renin-angiotensin system was shown in our recent study by Magaton et al. (29) in the same DO model. The concentration of angiotensin II (Ang II) in renal tissue was similar in the control and DO groups, but the concentration of angiotensin 1-7 (Ang 1-7), a vasodilator agent, was decreased, indicating that changes in the formation and/or degradation of Ang 1-7 may have occurred, leading to glomerular hypertrophy and contributing to hypertension. Ang 1-7, unlike Ang II, has been shown to have an important antiproliferative effect (45) As shown by Li et al. (46), the vasodilatation effect of Ang 1-7 on mouse aorta was abolished by the pretreatment of the vessels with L-NAME and also in vessels denuded from endothelium. These results pointed to endothelial NO as the final mediator of the Ang 1-7-induced vasodilatation.

In summary, in DO, L-arg increased vascular NO formation, decreased BP and suppressed local or systemic glomeruli hypertrophic stimuli, increasing the bioavailability of NO. Our studies reinforce the concept that maternal diabetic characteristics can be transmitted to the offspring, perpetuating some pathologic situations which can appear later in life. Moreover, DO rats can be regarded as a useful model to study the role of systemic hypertension in the progression of kidney injury, in a preserved nephron number model.

\section{REFERENCES}

1. Barker DJ, Osmond C, Golding J, Kuhn D, Wadsworth ME 1989 Growth in utero, blood pressure in childhood and adult life and mortality from cardiovascular disease. BMJ 298:564-567

2. Hales CN, Barker DJ, Clarck PM, Cox LJ, Fall C, Osmond C, Winter PD 1991 Fetal and infant growth and impaired glucose tolerance at age 64. BMJ 303:1019-1022

3. Barker DJ 1995 Fetal origins of coronary heart disease. BMJ 311:171-174

4. Pedersen LM, Tygstrup I, Pedersen J 1964 Congenital malformations in newborn infants of diabetic women. Correlation with maternal diabetic vascular complications. Lancet 13:1124-1126

5. Travers JP, Pratten MK, Beck F 1989 Effects of low insulin levels on rat embryonic growth and development. Diabetes 38:773-778

6. Garcia Carrapato MR 2003 The offspring of gestational diabetes. J Perinat Med 31:5-11

7. Nold JL, Georgieff MK 2004 Infants of diabetic mothers. Pediatr Clin North Am 51:619-637

8. Lynch SA, Wright C 1997 Sirenomelia, limb reduction defects, cardiovascular malformation, renal agenesis in an infant born to a diabetic mother. Clin Dysmorphol 6:75-80

9. Chugh SS, Wallner EI, Kanwar YS 2003 Renal development in high-glucose ambience and diabetic embryopathy. Semin Nephrol 23:583-592

10. Rich-Edwards JW, Colditz GA, Stampfer MJ, Willett WC, Gillman MW, Hennekens CH, Speizer FE, Manson JE 1999 Birthweight and the risk for type-2 diabetes mellitus in adult women. Ann Intern Med 130:278-284

11. Carlsson S, Persson PG, Alvarsson M, Efendic S, Norman A, Svanstrom L, Osterson AG, Grill V 1999 Low birth weight, family history of diabetes and glucose intolerance in Swedish middle-aged men. Diabetes Care 22:1043-1047

12. Manderson JG, Mullan B, Patterson CC, Hadden DR, Traub AI, McCance DR 2002 Cardiovascular and metabolic abnormalities in the offspring of diabetic pregnancy. Diabetologia 45:991-996

13. Holemans K, Gerber RT, Meurrens K, De Clerck F, Poston L, Van Assche FA 1999 Streptozotocin diabetes in the pregnant rat induces cardiovascular dysfunction in adult offspring. Diabetologia 42:81-89

14. Amri K, Freund N, Vilar J, Merlet-Benichou C, Lelièvre-Pegorier M 1999 Adverse effects of hyperglycemia on kidney development in rats: in vivo and in vitro studies. Diabetes 48:2240-2245

15. Rocha SO, Gomes GN, Forti AL, Pinho Franco MC, Fortes ZB, Cavanal MF, Zaladek Gil F 2005 Long term effects of maternal diabetes on vascular reactivity and renal function in rat male offspring. Pediatr Res 58:1274-1279

16. Lucas SR, Costa-Silva VL, Miraglia SM, Zaladek Gil F 1997 Functional and morphometric evaluation of offspring kidney after intrauterine undernutrition. Pediatr Nephrol 11:719-723

17. Lucas RS, Miraglia SM, Zaladek Gil F, Coimbra TM 2001 Intrauterine food restriction as a determinant of nephrosclerosis. Am J Kidney Dis 37:467-476

18. Alves GM, Barão MA, Odo LN, Nascimento Gomes G, Franco Md Mdo C, Nigro D, Lucas SR, Laurindo FR, Brandizzi LI, Zaladek Gil F 2002 L-arginine effects on blood pressure and renal function of intrauterine restricted rats. Pediatr Nephrol 17:856-862

19. Pinho Franco MC, Nigro D, Fortes ZB, Tostes RC, Carvalho MH, Lucas SR, Gomes GN, Coimbra TM, Gil FZ 2003 Intrauterine undernutrition-renal and vascular origin of hypertension. Cardiovasc Res 60:228-234

20. Gil FZ, Lucas SR, Gomes GN, Cavanal Mde F, Coimbra TM 2005 Effects of intrauterine food restriction and long-term dietary supplementation with L-arginine on age-related changes in renal function and structure of rats. Pediatr Res 57:724731

21. Reyes AA, Purkerson ML, Karl I, Klahr S 1992 Dietary supplementation with L-arginine ameliorates the progression of renal disease in rats with subtotal nephrectomy. Am J Kidney Dis 20:168-176

22. Reyes AA, Karl IE, Kissane J, Klahr S 1993 L-arginine administration prevents glomerular hyperfiltration and decreases proteinuria in diabetic rats. J Am Soc Nephrol 4:1039-1045

23. Boger RH, Bode-Boger S, Mugge A, Kienke S, Brandes R, Dwenger A, Frolich JC 1995 Supplementation of hypercholesterolemic rabbits with L-arginine reduces the vascular release of superoxide and restores NO production. Atherosclerosis 117:273-284

24. Reckelhoff JF, Kellum JA Jr, Racusen LC, Hildebrandt DA 1997 Long-term dietary supplementation with $\mathrm{L}$-arginine prevents age-related reduction in renal function. Am J Physiol 272:R1768-R1774 
25. National Research Council 1996 Guide for Care and use of Laboratory Animals. National Academic Press, Washington D.C., pp 8-116

26. Nelson RG, Morgenstern H, Bennett PH 1998 Intrauterine diabetes exposure and the risk of renal disease in diabetic Pima Indians. Diabetes 47:1489-1493

27. Srinivasan M, Aalinkeel R, Song F, Patel MS 2003 Programming of islet functions in the progeny of hyperinsulinemic/obese rats. Diabetes 52:984-990

28. Aerts L, Assche FA 2006 Animal evidence for the transgenerational development of diabetes mellitus. Int J Biochem Cell Biol 38:894-903

29. Magaton A, Gil FZ, Casarini DE, Cavanal Mde F, Gomes GN 2007 Maternal diabetes mellitus - early consequences for the offspring. Ped Nephrol 22:37-43

30. Yoshida Y, Fogo A, Ichiwaka I 1989 Glomerular hemodynamic changes vs. hypertrophy in experimental glomerulosclerosis. Kidney Int 35:654-660

31. Miller PL, Rennke HG, Meyer TW 1991 Glomerular hypertrophy accelerates hypertensive glomerular injury in rats. Am J Physiol 261:F459-F465

32. Klag MJ, Whelton PK, Randall BL, Neaton JD, Brancati FL, Ford CE, Shulman NB, Stalmer J 1996 Blood pressure and end-stage renal disease in men. N Engl J Med 334:13-18

33. Marcantoni C, Jafar TH, Oldrizzi L, Levey AS, Maschio G 2000 The role of systemic hypertension in the progression of nondiabetic renal disease. Kidney Int Suppl 75:S44-S48

34. Mount PF, Power DA 2006 Nitric oxide in the kidney: functions and regulation of synthesis. Acta Physiol (Oxf) 187:433-446

35. Zatz R, Baylis C 1998 Chronic nitric oxide inhibition model six years on. Hypertension 32:958-964

36. Schmidt RJ, Domico J, Samsell LS, Yokota S, Tracy TS, Sorkin MI, Engels K, Baylis C 1999 Indices of activity of the nitric oxide system in hemodialysis patients. Am J Kidney Dis 34:228-234
37. Baylis C 2006 Arginine, arginine analogs and nitric oxide production in chronic kidney disease. Nat Clin Pract Nephrol 2:209-220

38. Liang M, Knox FG 1999 Nitric oxide reduces de molecular activity of Na-K-ATPase in the opossum kidney cells. Kidney Int 56:627-634

39. Garvin JL, Ortiz PA 2003 The role of reactive oxygen species in the regulation of tubular function. Acta Physiol Scand 179:225-232

40. Taylor PD, Graves JE, Poston L 1995 Selective impairment of acetylcholinemediated endothelium-dependent relaxation in isolated resistance arteries of the streptozotocin-induced diabetic rat. Clin Sci 88:519-524

41. Pieper GM, Dondlinger LA 1997 Plasma and vascular tissue arginine are decreased in diabetes: acute arginine supplementation restores endothelium-dependent relaxation by augmenting cGMP production. J Pharmacol Exp Ther 283:684-691

42. Tayek JÁ, Katz J 1996 Glucose production, recycling, and gluconeogenesis in normals and diabetics: a mass isotopomer [U-13C]glucose study. Am J Physiol 270:E709-E717

43. Arkhipova MM, Neooev VV, Baratova LL, Lysenko VS 2000 L-arginine in the lacrimal fluid of patients with diabetic retinopathy and possible role of nitric oxide in the pathogenesis of retinal ischemia. Vestn Oftalmol 116:23-24

44. Pieper GM, Peltier BA 1995 Amelioration by L-arginine of a dysfunctional Larginine/nitric oxide pathway in diabetic endothelium. J Cardiovasc Pharmacol 25:397-403

45. Tallant EA, Clark MA 2003 Molecular mechanisms of inhibition of vascular growth by angiotensin- (1-7). Hypertension 42:574-579

46. Li P, Chappell MC, Ferrario CM, Brosnihan KB 1997 Angiotensin (1-7) augments bradykinin-induced vasodilation by competing with ACE and releasing nitric oxide. Hypertension 29:394-400 